\title{
Triplet Chemotherapy (FOLFOXIRI) Plus Bevacizumab Versus Doublet Chemotherapy (FOLFOX/FOLFIRI) Plus Bevacizumab in Conversion Therapy for Metastatic Colorectal Cancer: a Meta- Analysis
}

\author{
Lin Shuia,d $\quad$ Yu-Shen Wu ${ }^{a} \quad$ Huapeng Lin ${ }^{b}$ Pixian Shuic ${ }^{c}$ Qin Sun ${ }^{\mathrm{e}}$ \\ Xiaopin Chen ${ }^{\text {a }}$
}

\begin{abstract}
aDepartment of Oncology, The First Affiliated Hospital of Chongqing Medical University, Chongqing, bDepartment of Hepatobiliary Surgery, The Second Affiliated Hospital of Chongqing Medical University, Chongqing, 'School of Pharmacy, Southwest Medical University, Sichuan, dWest China Medical Center, Sichuan University, Chengdu, Sichuan, eThe Affiliated Traditional Chinese Medicine Hospital of Southwest Medical University, Sichuan, P.R. China
\end{abstract}

\section{Key Words}

Folfoxiri • Bevacizumab $\bullet$ Colorectal cancer $\bullet$ Conversion therapy $\bullet$ R0 resection

\begin{abstract}
Background/Aims: Conversion therapy can convert unresectable metastatic colorectal cancer $(m C R C)$ into resectable. However, the optimal conversion regimen was not yet defined. This meta-analysis aimed to compare the efficacy and safety of the triplet chemotherapy (FOLFOXIRI) plus bevacizumab (Bev) with doublet chemotherapy (FOLFOX/FOLFIRI) plus Bev in conversion therapy. Methods: Randomized controlled trials (RCTs) from databases, including Pubmed, EMBASE, Cochrane clinical trials, clinicaltrial.gov and some conferences, were searched from the inception to November 2017. The R0 resection, objective response rate (ORR), progression-free survival (PFS), overall survival (OS) and the incidence of adverse events were pooled with the use of hazard ratio (HR) or risk ratio (RR). Results: Four RCTs with 1013 patients were included. FOLFOXIRI plus Bev regimen significantly improved the overall R0 resection rate (RR $1.41,95 \%$ confidence interval (CI) $1.07-1.85, \mathrm{I}^{2}=37 \%$ ), liver R0 resection rate (RR 2.28, 95\% CI 1.34-3.89, I $\mathrm{I}^{2}=0 \%$ ), ORR (RR 1.20, 95\% CI 1.09-1.32, $\mathrm{I}^{2}=0 \%$ ), PFS (HR 0.72, 95\% CI 0.62-0.84, $\mathrm{I}^{2}=36 \%$ ) and OS (HR 0.80, 95\% CI 0.66-0.97, I $\mathrm{I}^{2}=0 \%$ ). There was no significant difference in any Grade $\geq 3$ adverse event (RR 1.08, 95\% CI 0.99-1.17, I²=0\%) between two regimens. FOLFOXIRI-Bev was associated with a higher risk of neutropenia (RR 1.77, 95\% CI 1.13-2.79, $\mathrm{I}^{2}=68 \%$ ) and diarrhea (RR 1.65, 95\% CI 1.17-2.32, $\mathrm{I}^{2}=0 \%$ ). Conclusions:
\end{abstract}

Lin Shui, Yu-Shen Wu and Huapeng Lin contributed equally to this work.

Xiaopin Chen and Qin Sun

KARGER
Department of Oncology, The First Affiliated Hospital of Chongqing Medical University Chongqing (P.R. China) and The Affliated Traditional Chinese Medicine Hospital of Southwest Medical University, Sichuan, (P.R. China), E-Mail xiaopinchen123@163.com; sdy-0502@126.com 
Triplet chemotherapy plus Bev significantly improved the RO resection rates, ORR, PFS and OS in comparison with doublet chemotherapy plus Bev in conversion therapy for $\mathrm{mCRC}$ patients, with a higher risk of neutropenia and diarrhea.

(C) 2018 The Author(s)

Published by S. Karger AG, Basel

\section{Introduction}

Colorectal cancer (CRC) is the third most frequently occurring cancer, with the second most common cause of death in men and third in female [1]. Approximately $25 \%$ of patients who initially diagnosed colorectal cancer have synchronous liver metastasis, while another $25 \%$ of patients will develop liver metastasis after radical resection of the primary lesion [2]. Evidence indicated that the resection of metastases had significant survival benefits and offers the possibility of cure $[3,4]$. The 5-year survival rate in patients with unresectable liver metastases is close to $0 \%$ [5], while in patients with resectable metastatic patients it approaches $43 \%-50 \%[6,7]$. Additionally, $10 \%-20 \%$ of metastases are found in the lung s and the resection of lung metastases provides 5 -year survival rates of $25 \%-35 \%$ in carefully selected patients. And the European Society of Medical Oncology (ESMO) guidelines also recommend $\mathrm{R} 0$ resection of lung metastases [8].

Conversion therapy transforms technically unresectable colorectal metastases into resectable status by systemic therapy, and the majority (80\%-90\%) of the liver metastases can not get radical resection [2]. The overall survival of patients who undergo radical surgery after conversion therapy is close to patients with initially resectable metastatic CRC (mCRC) [9-11]. Thus, to obtain optimal regression of metastases, unresectable mCRC patients should take a more aggressive treatment with the application of effective strong chemotherapeutic regimen [12].

Bevacizumab (Bev) plus triplet regimen (FOLFOXIRI-leucovorin, fluorouracil, oxaliplatin, and irinotecan) and doublet regimens (FOLFOX-leucovorin, fluorouracil, and oxaliplatin; FOLFIRI-leucovorin, fluorouracil, and irinotecan) are both standard options for conversion therapy [12]. Studies have reported that FOLFOXIRI regimen can improve survival benefits compared with FOLFIRI $[13,14]$, which is also validated in a meta-analysis [15]. A randomized controlled trial (RCT) comparing FOLFOX-Bev with FOLFIRI-Bev showed that both had equivalent activity and efficacy in patients with mCRC [16]. Recently, a pooled analysis showed that the probability of conversion in patients with mCRC approached nearly $40 \%$ with the use of FOLFOXIRI-Bev [17]. However, the comparison between FOLFOXIRIBev and FOLFOX-Bev/FOLFIRI-Bev has never been systematically evaluated in conversion therapy. Considering the FOLFOXIRI-Bev regimen could be associated with more toxicity, this systematic review and meta-analysis were performed to compare the efficacy and safety of FOLFOXIR-Bev with FOLFOX-Bev/FOLFIRI-Bev.

\section{Materials and Methods}

\section{Literature search and inclusion criteria}

Focused on published RCT, articles from databases including Pubmed, EMBASE and Cochrane clinical trials were searched from the inception to November 2017. The databases of Clinicaltrial.gov, American Society of Clinical Oncology (ASCO) and ESMO were also searched. The searching terms were used: "FOLFOXIRI", "FOLFOX", “FOLFIRI", "XELOX", "bevacizumab", "Avastin", and "colorectal cancer". Evidence showed that FOLFOX-Bev and FOLFIRI-Bev had equivalent efficacy [16], including objective response rate (ORR), progression-free survival (PFS) and overall survival (OS), so both FOLFOX-Bev and FOLFIRI-Bev regimens were included in the control group. No limit language of the published articles. In addition, no trials using XELOX were searched to meet our inclusion criteria.

The purpose of this meta-analysis was to establish the link between two regimens, thus only RCTs that directly compare the two regimens could be included. The inclusion criteria were as follows: (1) phase 2 or 3 trials involving patients with mCRC; (2) patients who were randomized to FOLFOXIRI-Bev or FOLFOX- 


\section{Cellular Physiology Cell Physiol Biochem 2018;48:1870-1881

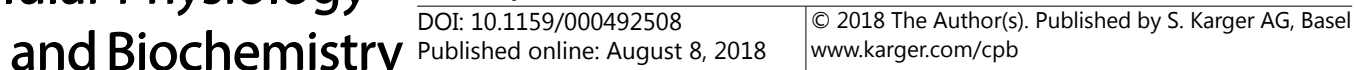

Bev/FOLFIRI-Bev regimens; (3) available data that can be pooled. Two investigators searched and reviewed all identified studies independently. If the two investigators were not able to reach a consensus about the eligibility of an article, it was resolved by discussions with a third reviewer.

\section{Data extraction and quality assessment}

The following data were extracted from each study by two investigators independently: the primary endpoint, publication year, characteristics of enrolled patients, study design, the regimens of chemotherapy, the number of participants, and outcomes of the various subgroup. The data of outcome were extracted as follow: the R0 resection rate of metastases, ORR, PFS, OS and the incidence of adverse events. When a trial had two intervention groups, only one intervention group that most closely resembles the other trials was selected [18]. Focused on conversion therapy, R0 resection rate was the primary outcome of our study. According to the incidence of events, the five most common adverse events were selected for analysis.

The quality of included trials was assessed with the use of the Cochrane Collaboration's tool and with reference to the Cochrane handbook. The risk of bias assessment was expressed in three types: low risk $(+)$, unclear risk (?) or high risk (-) of bias for each study [18]. Part of the data and quality evaluation were based on data published on clinicaltrial.gov. All process was performed by two reviewers independently and disagreements were discussed to reach a consensus.

\section{Statistical analysis}

The meta-analysis was conducted using RevMan software version 5.3 (The Nordic Cochrane Center, Cochrane Collaboration). The 95\% confidence interval (CI) of all results was calculated and extracted. Timeto-event endpoints (PFS and OS) were pooled with the use of hazard ratio (HR). In survival analysis, the hazard ratio can be interpreted as the incidence of progress or death. The ORR, the R0 resection rates and incidence of adverse events were pooled through risk ratio (RR). Subgroup analyses were adopted to assess the outcomes of patients with different RAS or BRAF status. All the outcome were extracted directly from the reports. Heterogeneity among the included studies was qualitatively evaluated using a $\chi^{2}$-based Q test [18]. The $\mathrm{P}_{\text {heterogeneity }}$ less than 0.05 showed that there was significant heterogeneity across the studies [15]. The level of statistical heterogeneity between studies was evaluated by $\mathrm{I}^{2}$ statistics [19]. When $\mathrm{I}^{2}$ was less than $30 \%, 30 \%$ to $50 \%$ and more than $50 \%$, respectively, there was a low, moderate and high heterogeneity [20].. The fixed-effects was applied when $\mathrm{I}^{2} \leq 50 \%$, and the randomeffects model was applied when $\mathrm{I}^{2} \geq$ $50 \%$ [21]. Due to the small number of included trials $(<10)$, we did not examine publication bias with Begg and Egger tests [18, 22, 23].

\section{Results}

Characteristics and quality of included studies

Totally four RCTs with 1013 patients were included in the meta-analysis [24-27]. Some data were updated by the results of subsequent reports [28-30]. The process of study selection is illustrated in Fig. 1. By reason of study protocol, we ruled out four trials, which used Bev in maintenance therapy or used both Bev and Cetuximab in the experimental group. The main

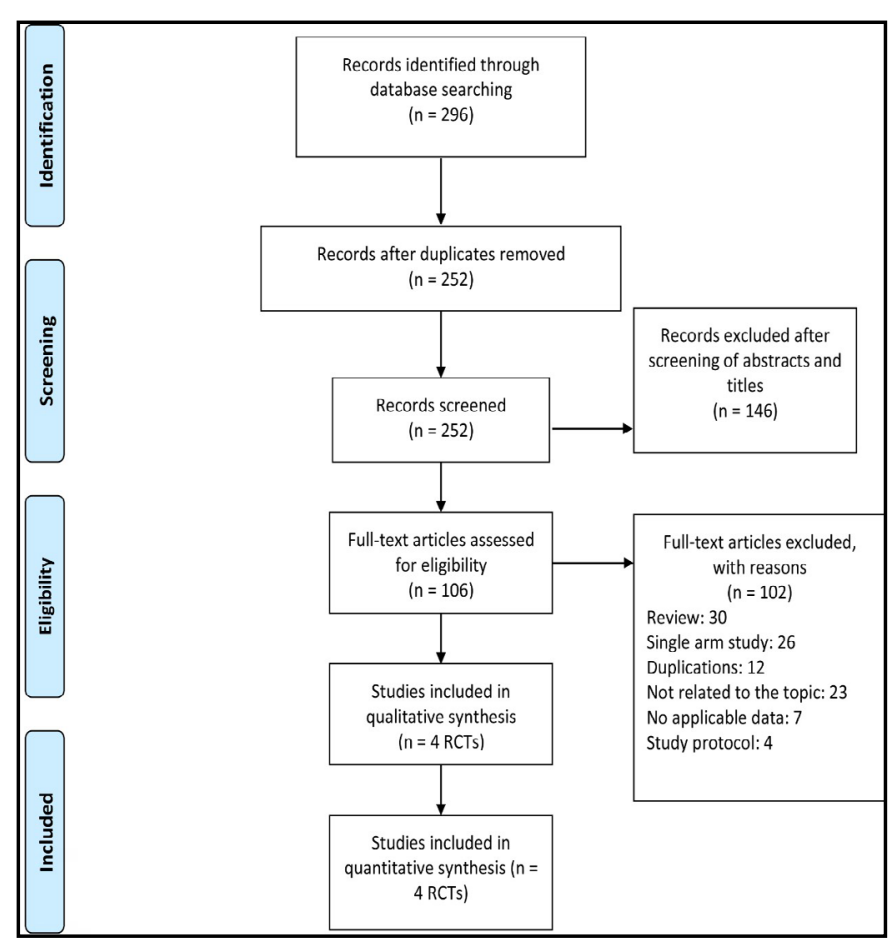

Fig.1. Flow diagram of search process. 
characteristics of four RCTs were summarized in Table 1. The STEAM, CHARTA, and OLIVIA trials were phase 2 RCTs and the control groups received the FOLFOX regimen; the TRIBE trial was phase 3 RCT and the control group received the FOLFIRI regimen. Conversion therapy cycle was 8-12 cycles. For the inclusion criteria of patients, OLIVIA enrolled patients with only liver metastases, and the other trials enrolled patients without this limitation. The patients with previously untreated mCRC were enrolled in the OLIVIA and CHARTA trials. While the TRIBE trial enrolled patients who had not received therapy for metastases but may have received adjuvant chemotherapy before metastases.

The efficacy results of included trials are presented in Table 2. The R0 resection rate, ORR, PFS and OS were reported in four RCTs. And the PFS for mCRC patients in RAS and BRAF subgroups is demonstrated in Table 3. Due to STEAM and CHARTA tests were published as abstract, the random generation, attrition bias, and other bias were judged as unclear. The outcome of the trials was not likely to be affected by the lack of blinding, therefore, performance bias and detection bias were judged as low risk [18]. The risk of bias was summarized as low risk (Fig. 2).
Table 1. Characteristics of four RCTs. PFS, progression-free survival; ORR, overall response rate; ECOG, Eastern Cooperative Oncology Group; PS, performance status; IRI, irinotecan; FOL, leucovorin; F, fluorouracil; OX, oxaliplatin; Bev, bevacizumab; mCRC, metastatic colorectal cancer

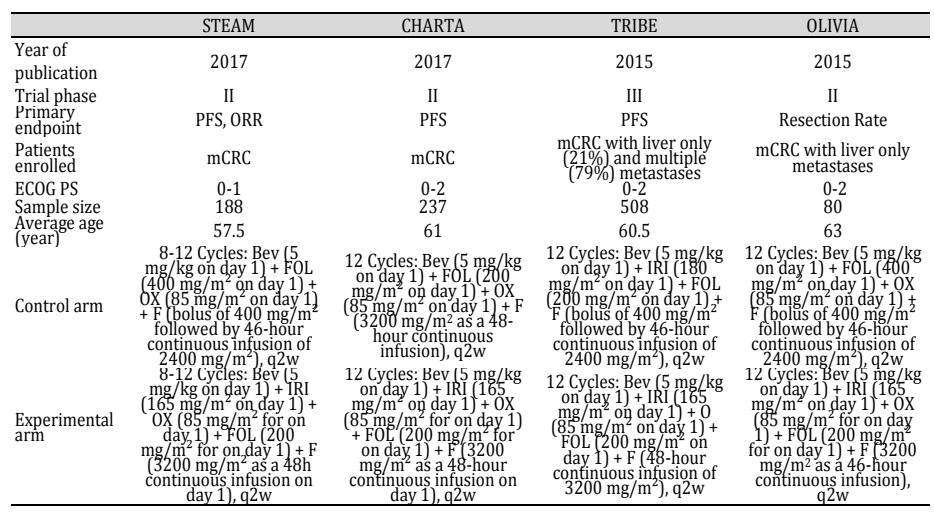

Table 2. Efficacy results of four RCTs. PFS, progression-free survival; OS, overall survival; ORR, objective response rate; FOLFOXIRI, leucovorin + fluorouracil + oxaliplatin + irinotecan; FOLFOX, leucovorin + fluorouracil + oxaliplatin; FOLFIRI, leucovorin + fluorouracil +Irinotecan; Bev, bevacizumab

\begin{tabular}{|c|c|c|c|c|c|c|c|c|c|}
\hline & & $\begin{array}{r}S \\
\text { FOLLFXIR } \\
\text { Bev }\end{array}$ & FOLFOX- & $\begin{array}{r}\text { CHA } \\
\text { FOLFOXIRI- } \\
\text { Bev }\end{array}$ & $\begin{array}{l}\text { TA } \\
\text { FOLFOX- } \\
\text { Bev }\end{array}$ & 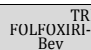 & $\begin{array}{l}\mathrm{E}_{\text {FOLFIRI- }} \\
\text { Bev }\end{array}$ & $\begin{array}{r}\text { OLI } \\
\begin{array}{c}\text { FOLFOXIRI- } \\
\text { Bev }\end{array}\end{array}$ & $\begin{array}{l}\text { IA } \\
\text { FOLFOX } \\
\text { Bev }\end{array}$ \\
\hline \multirow{2}{*}{ PFS } & $\begin{array}{l}\text { Median } \\
\text { (months) }\end{array}$ & 12 & 10 & 12 & 9.7 & 12.3 & 9.7 & 18.6 & 11.5 \\
\hline & $\begin{array}{l}\mathrm{HR}(90 \%) \\
\mathrm{Cl}\end{array}$ & \multicolumn{2}{|c|}{$0.7(0.5,0.9)$} & \multicolumn{2}{|c|}{$0.77(0.33-1.78)$} & \multicolumn{2}{|c|}{$0.77(0.66-0.88)$} & \multicolumn{2}{|c|}{$0.43(0.28-0.65)$} \\
\hline \multirow{3}{*}{ OS } & $\begin{array}{c}\text { Median } \\
\text { (months) }\end{array}$ & 34 & 31 & - & & 29.8 & 25.8 & \multicolumn{2}{|c|}{ - } \\
\hline & $\begin{array}{l}\mathrm{HR}(\mathrm{yuO} \% \\
\mathrm{Cl})\end{array}$ & \multicolumn{2}{|c|}{$0.8(0.5,1.2)$} & \multicolumn{2}{|c|}{-} & \multicolumn{2}{|c|}{$0.80(0.67-0.95)$} & \multicolumn{2}{|r|}{ 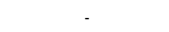 } \\
\hline & (1) & 72 & 62 & 70 & 60 & 65.1 & 53.1 & 81 & 62 \\
\hline \multirow{2}{*}{$\begin{array}{l}\text { R0 } \\
\text { Resection } \\
\text { rate (\%) }\end{array}$} & $\begin{array}{l}\text { Overall RU } \\
\text { resection } \\
(\%)\end{array}$ & 15 & 6 & 23 & 21 & 15 & 12 & 54 & 31 \\
\hline & $\begin{array}{l}\text { Livection } \\
\text { rection } \\
(\%)\end{array}$ & 15 & 6 & - & - & & & 49 & 23 \\
\hline
\end{tabular}

Table 3. Progression-free survival in RAS and BRAF subgroups. FOLFOXIRI, leucovorin + fluorouracil + oxaliplatin + irinotecan; FOLFOX, leucovorin + fluorouracil + oxaliplatin; FOLFIRI, leucovorin + fluorouracil +Irinotecan; Bev, bevacizumab; wt, wild-type; mut, mutation

\begin{tabular}{|c|c|c|c|c|c|c|c|c|}
\hline \multirow[b]{2}{*}{ GENOTYPE } & \multirow[b]{2}{*}{ PFS } & \multicolumn{2}{|c|}{ STEAM } & \multicolumn{2}{|c|}{ CHARTA } & \multicolumn{2}{|c|}{ TRIBE } & \multirow{2}{*}{$\begin{array}{c}\text { POOLED } \\
\text { PFS } \\
\text { HR ( } 90 \% \\
\text { CI) }\end{array}$} \\
\hline & & $\begin{array}{l}\text { FOLFOXIRI- } \\
\text { Bev }\end{array}$ & $\begin{array}{l}\text { FOLFOX- } \\
\text { Bev }\end{array}$ & $\begin{array}{l}\text { FOLFOXIRI- } \\
\text { Bev }\end{array}$ & $\begin{array}{l}\text { FOLFOX- } \\
\text { Bev }\end{array}$ & $\begin{array}{l}\text { FOLFOXIRI- } \\
\text { Bev }\end{array}$ & $\begin{array}{c}\text { FOLFIRI- } \\
\text { Bev }\end{array}$ & \\
\hline \multirow[b]{2}{*}{ BRAF mut } & 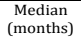 & 7 & 12 & 10.1 & 7.8 & $7 \cdot 5$ & $5 \cdot 5$ & \multirow{3}{*}{$\begin{array}{c}0.65 \\
(0.33- \\
1.26)\end{array}$} \\
\hline & $\begin{array}{l}\text { HR }(90 \% \\
\text { Cl) }\end{array}$ & \multicolumn{2}{|c|}{$0.8(0.2,3.0)$} & \multicolumn{2}{|c|}{$0.72(0.25-2.07)$} & \multicolumn{2}{|c|}{$0.57(0.27-1.23)$} & \\
\hline \multirow[b]{2}{*}{ RAS wt } & $\begin{array}{c}\text { Median } \\
\text { (months) }\end{array}$ & 17 & 10 & 13.1 & 9.6 & 12.8 & 11.0 & \\
\hline & $\begin{array}{l}\text { HR }(90 \% \\
\text { Cl) }\end{array}$ & \multicolumn{2}{|c|}{$0.6(0.4,1.1)$} & \multicolumn{2}{|c|}{$0.70(0.58-1.02)$} & \multicolumn{2}{|c|}{$0.84(0.58-1.21)$} & $\begin{array}{c}0.77 \\
(0.60- \\
0.98)\end{array}$ \\
\hline \multirow[b]{2}{*}{ RAS mut } & $\begin{array}{c}\text { Median } \\
\text { (months) }\end{array}$ & 13 & 8 & 12.3 & 10.4 & $12 \cdot 0$ & $9 \cdot 5$ & \\
\hline & $\begin{array}{c}\text { HR }(90 \% \\
\mathrm{Cl})\end{array}$ & \multicolumn{2}{|c|}{$0.6(0.4,1.0)$} & \multicolumn{2}{|c|}{$0.82(0.59-1.14)$} & \multicolumn{2}{|c|}{$0 \cdot 78(0 \cdot 60-1 \cdot 02)$} & $\begin{array}{c}0.77 \\
(0.61- \\
0.96) \\
\end{array}$ \\
\hline
\end{tabular}

\section{$R 0$ resection rate}

As an important result in conversion therapy, $\mathrm{R} 0$ resection rates were reported in all four RCTs. The pooled RR of overall R0 resection rate (any site of metastases) was 1.41 (95\% CI 1.07-1.85, $\left.\mathrm{I}^{2}=37 \%\right)$. To liver R0 resection rate, the pooled RR of two trials was $2.28(95 \%$ CI $1.34-3.89, \mathrm{I}^{2}=0 \%$ ). There was an increase of $36 \%$ in the overall R0 resection rate and $128 \%$ in liver R0 resection rate over doublet chemotherapy plus Bev (Fig. 3). 


\section{Objective response rate}

FOLFOXIRI-Bev was associated with a clear benefit in ORR. The pooled RR was 1.20 (95\% CI 1.09-1.32, $\mathrm{I}^{2}=0 \%$ ). With the development of surgical techniques and conceptions, a high ORR would increase the probability of conversion to resectable mCRC (Fig. 4).

\section{Survival benefits}

As the primary endpoint of three trials, the PFS was significantly improved (HR 0.72, $95 \%$ CI $\left.0.62-0.84, I^{2}=36 \%\right)$ in FOLFOXIRI-Bev group. And the pooled HR of OS was $0.80(95 \%$ CI 0.66-0.97, $\mathrm{I}^{2}=0 \%$ ) (Fig. 5). The results of median PFS and median OS are presented in the Table2. Subgroup analysis showed that FOLFOXIRI-Bev prolonged the PFS in mCRC patients with RAS wild-type (HR $0.77,95 \%$ CI $0.60-0.98, \mathrm{I}^{2}=0 \%$ ) or those with RAS mutation (HR $0.77,95 \%$ CI $0.61-0.96, I^{2}=0 \%$ ). There was no difference in PFS for BRAF mutation patients between two regimens (HR 0.65, 95\% CI 0.33-1.26, I²=0\%) (Fig. 6).

\section{Adverse events}

The pooled RRs of any Grade $\geq 3$ adverse events and five common adverse events (Grade $\geq 3$ ) are presented in Fig. 7. There was no significant difference in any Grade $\geq 3$ adverse events (RR 1.08, 95\% CI 0.99-1.17, $\mathrm{I}^{2}=0 \%$ ) between two regimens. FOLFOXIRI-Bev was associated with a higher risk of neutropenia (RR 1.77, 95\% CI 1.13-2.79, $\mathrm{I}^{2}=68 \%$ ) and diarrhea (RR $1.65,95 \%$ CI 1.17-2.32, $\left.I^{2}=0 \%\right)$. Between two regimens, the incidence of febrile neutropenia, vomiting, and venous thrombosis was no difference as follows: febrile neutropenia (RR 1.43, 95\% CI 0.81-2.51, $\mathrm{I}^{2}=0 \%$ ), vomiting (RR $1.54,95 \%$ CI $0.67-3.54, I^{2}=0 \%$ ), and venous thrombosis (RR $0.91,95 \%$ CI $\left.0.39-2.14, \mathrm{I}^{2}=36 \%\right)$.

\section{Discussion}

The significant survival benefit of mCRC patients who become resectable after conversion therapy is close to initially resectable patients, which

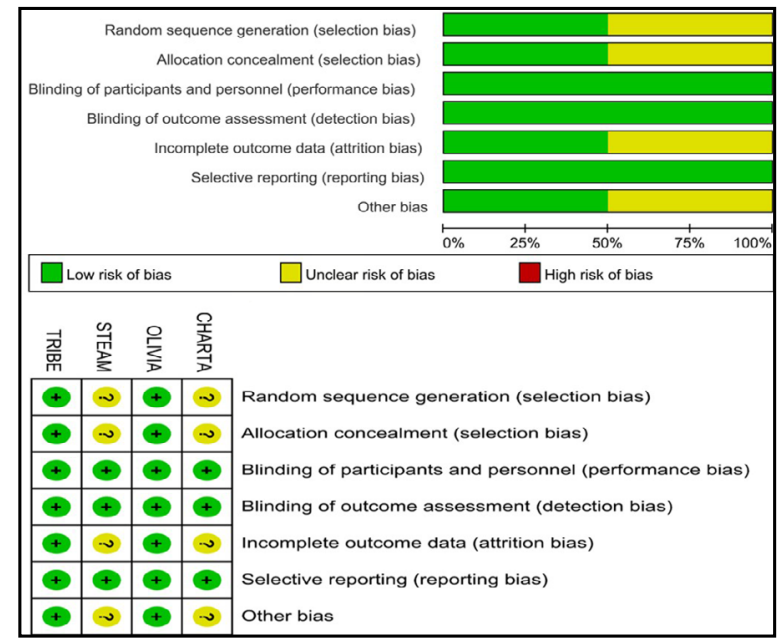

Fig. 2. Risk of bias summary.

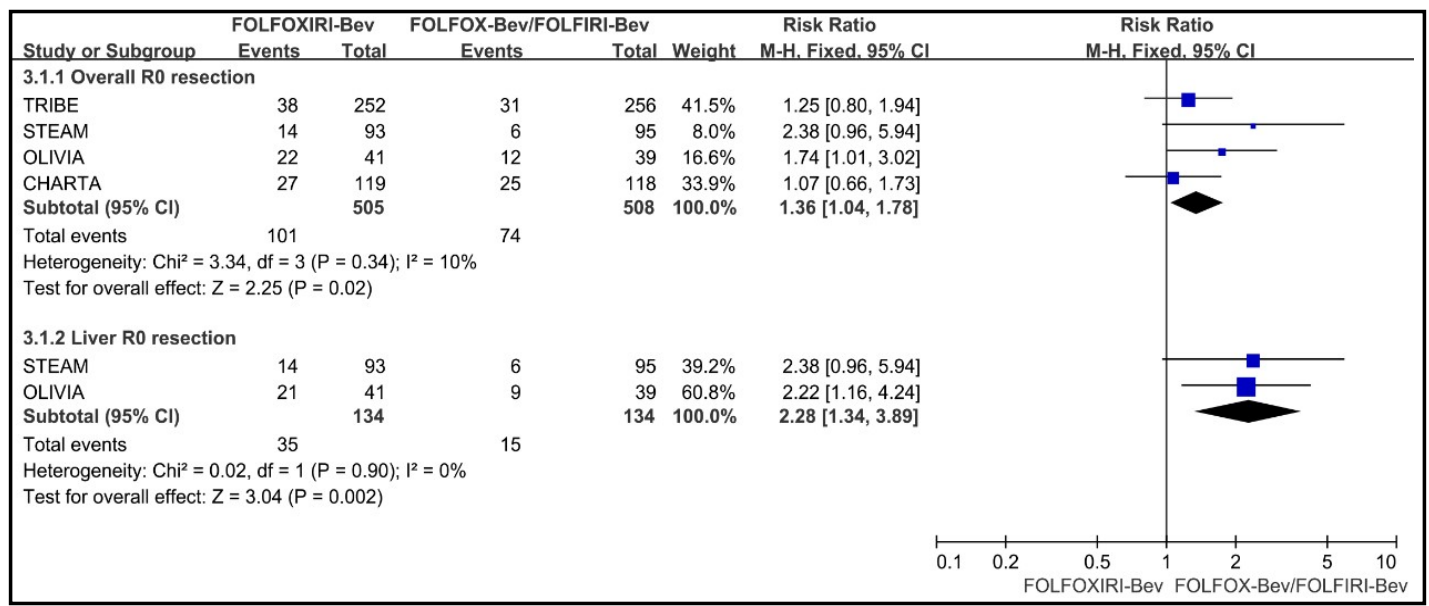

Fig. 3. Forest plots for R0 resection rate. 
Cellular Physiology Cell Physiol Biochem 2018;48:1870-1881

\begin{tabular}{l|l} 
and Biochemistry Published online: August 8, 2018 & $\begin{array}{l}\text { () 2018 The Author(s). Published by S. Karger AG, Basel } \\
\text { www.karger.com/cpb }\end{array}$ \\
\hline
\end{tabular}

Shui et al.: FOLFOXIRI plus Bevacizumab in mCRC Conversation Therapy

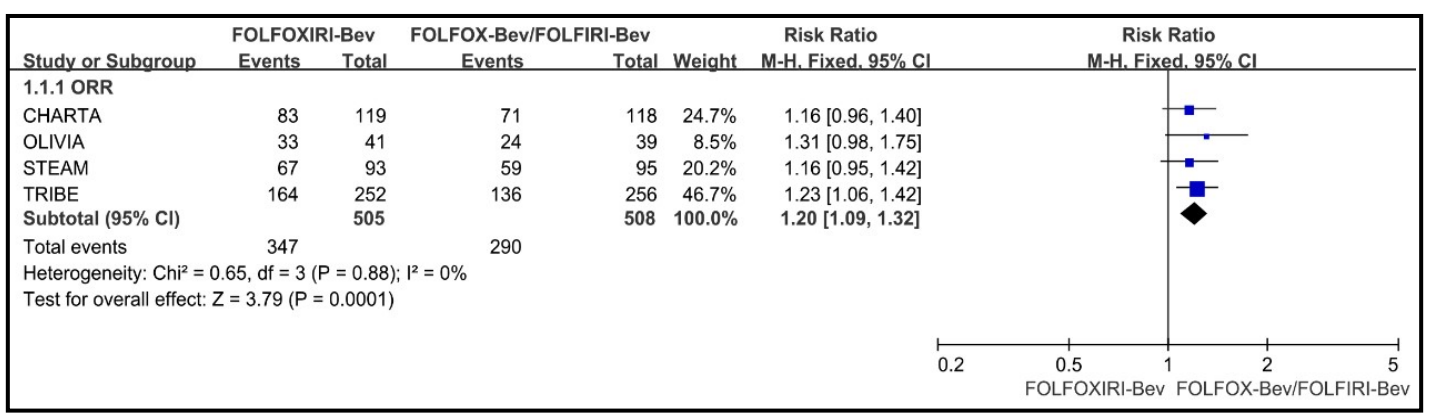

Fig. 4. Forest plots for objective response rate.

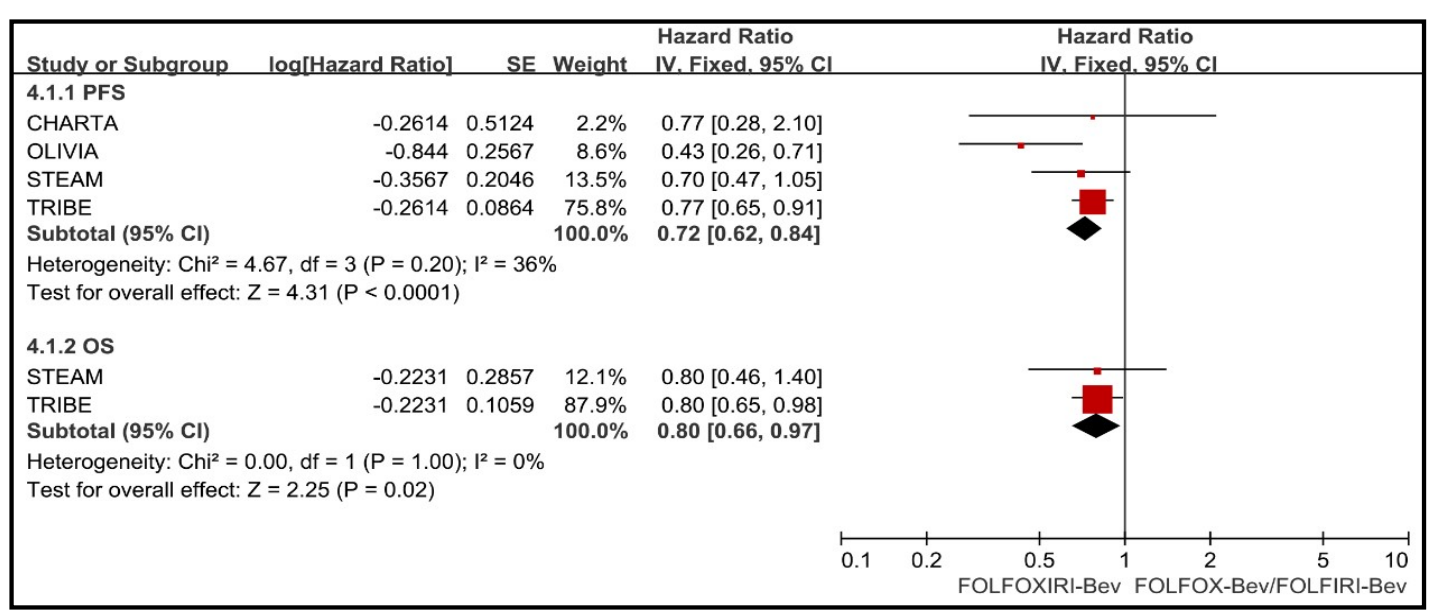

Fig. 5. Forest plot for survival benefits.

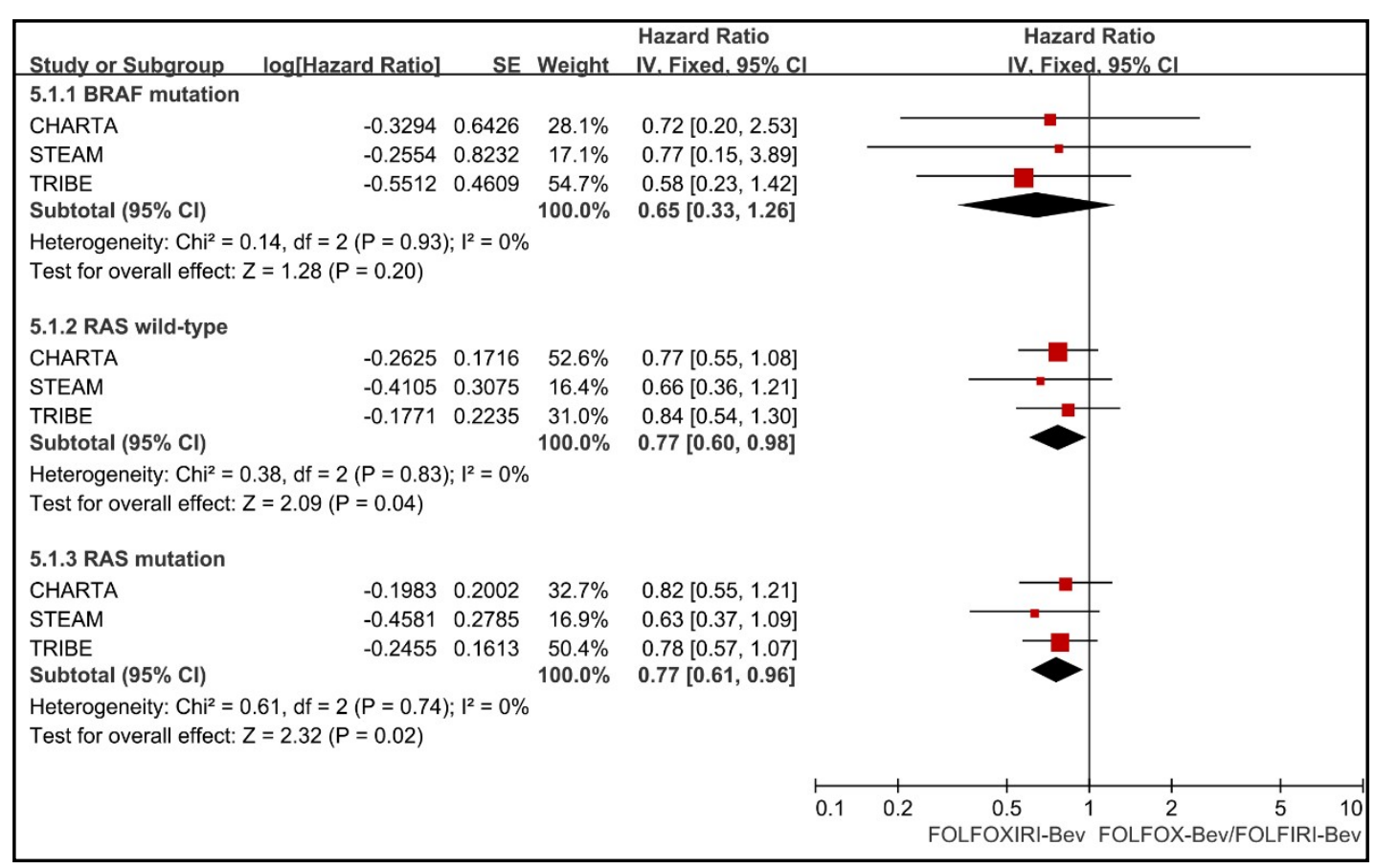

Fig. 6. Forest plot for PFS in the subgroup. 


\begin{tabular}{|c|c|c|c|c|c|c|c|c|c|}
\hline \multirow{2}{*}{ Study or Subgroup } & \multicolumn{2}{|c|}{ FOLFOXIRIIBev } & \multicolumn{2}{|c|}{ FOLFOX-Bev/FOLFIRI-Bev } & \multirow{2}{*}{\multicolumn{2}{|c|}{$\begin{array}{c}\text { Risk Ratio } \\
\text { Weight } \quad \text { M-H. Random. } 95 \% \mathrm{Cl}\end{array}$}} & \multirow{2}{*}{\multicolumn{3}{|c|}{$\begin{array}{ll} & \text { Risk Ratio } \\
\text { M.H. Random. } 95 \% \mathrm{Cl}\end{array}$}} \\
\hline & Events & Total & Events & Total & & & & & \\
\hline \multicolumn{10}{|c|}{ 2.1.1 Any adverse event (Grade $\geqslant 3$ ) } \\
\hline OLIVIA & 39 & 41 & 33 & 39 & $31.2 \%$ & $1.12[0.97,1.31]$ & & & \\
\hline STEAM & 85 & 93 & 82 & 95 & $68.8 \%$ & $1.06[0.96,1.17]$ & & & \\
\hline Subtotal $(95 \% \mathrm{Cl})$ & & 134 & & 134 & $100.0 \%$ & $1.08[0.99,1.17]$ & & & $\rightarrow$ \\
\hline Total events & 124 & & 115 & & & & & & \\
\hline \multicolumn{10}{|c|}{ Heterogeneity: $\mathrm{Tau}^{2}=0.00 ; \mathrm{Ch}^{2}=0.42, \mathrm{df}=1(P=0.52) ; \mathrm{l}^{2}=0 \%$} \\
\hline \multicolumn{10}{|c|}{ Test for overall effect: $Z=1.77(P=0.08)$} \\
\hline \multicolumn{10}{|c|}{ 2.1.2 Neutropenia (Grade $\geqslant 3$ ) } \\
\hline CHARTA & 24 & 119 & 17 & 118 & $28.0 \%$ & $1.40[0.79,2.47]$ & & & \\
\hline OLIVIA & 20 & 41 & 14 & 39 & $29.9 \%$ & $1.36[0.80,2.29]$ & & & \\
\hline TRIBE & 126 & 252 & 51 & 256 & $42.0 \%$ & $2.51[1.91,3.30]$ & & & \\
\hline Subtotal $(95 \% \mathrm{Cl})$ & & 412 & & 413 & $100.0 \%$ & $1.77[1.13,2.79]$ & & & \\
\hline Total events & 170 & & 82 & & & & & & \\
\hline \multirow{2}{*}{\multicolumn{10}{|c|}{ Heterogeneity: $\mathrm{Tau}^{2}=0.11 ; \mathrm{Ch}^{2}=6.20, \mathrm{df}=2(\mathrm{P}=0.04) ; \mathrm{I}^{2}=68 \%$}} \\
\hline & & & & & & & & & Test for overall effect: $Z=2.47(P=0.01)$ \\
\hline \multicolumn{10}{|c|}{ 2.1.3 Febrile neutropenia (Grade $\geqslant 3$ ) } \\
\hline OLIVIA & 5 & 41 & 3 & 39 & $17.2 \%$ & $1.59[0.41,6.19]$ & & & \\
\hline TRIBE & 22 & 252 & 16 & 256 & $82.8 \%$ & $1.40[0.75,2.60]$ & & & \\
\hline Subtotal $(95 \% \mathrm{Cl})$ & & 293 & & 295 & $100.0 \%$ & $1.43[0.81,2.51]$ & & & \\
\hline \multirow{2}{*}{\multicolumn{10}{|c|}{ Heterogeneity: $\mathrm{Tau}^{2}=0.00 ; \mathrm{Chi}^{2}=0.03, \mathrm{df}=1(P=0.87) ;\left.\right|^{2}=0 \%$}} \\
\hline & & & & & & & & & \\
\hline \multicolumn{10}{|c|}{ Test for overall effect: $Z=1.24(P=0.22)$} \\
\hline \multicolumn{10}{|c|}{ 2.1.4 Vomiting (Grade $\geqslant 3$ ) } \\
\hline OLIVIA & 3 & 41 & 1 & 39 & $13.9 \%$ & $2.85[0.31,26.28]$ & & & \\
\hline TRIBE & 11 & 252 & 8 & 256 & $86.1 \%$ & $1.40[0.57,3.41]$ & & & \\
\hline Subtotal $(95 \% \mathrm{Cl})$ & & 293 & & 295 & $100.0 \%$ & $1.54[0.67,3.54]$ & & & \\
\hline Total events & 14 & & 9 & & & & & & \\
\hline \multicolumn{10}{|c|}{ Heterogeneity: $\mathrm{Tau}^{2}=0.00 ; \mathrm{Ch}^{2}=0.34, \mathrm{df}=1(\mathrm{P}=0.56) ; \mathrm{I}^{2}=0 \%$} \\
\hline \multicolumn{10}{|c|}{ Test for overall effect: $Z=1.03(P=0.31)$} \\
\hline \multicolumn{10}{|c|}{ 2.1.5 Diarrhea (Grade $\geqslant 3$ ) } \\
\hline CHARTA & 19 & 119 & 14 & 118 & $28.2 \%$ & $1.35[0.71,2.56]$ & & & \\
\hline OLIVIA & 12 & 41 & 5 & 39 & $13.0 \%$ & $2.28[0.89,5.88]$ & & & \\
\hline TRIBE & 45 & 252 & 27 & 256 & $58.8 \%$ & $1.69[1.09,2.64]$ & & & \\
\hline Subtotal $(95 \% \mathrm{Cl})$ & & 412 & & 413 & $100.0 \%$ & $1.65[1.17,2.32]$ & & & \\
\hline Total events & 76 & & 46 & & & & & & \\
\hline \multirow{2}{*}{\multicolumn{10}{|c|}{$\begin{array}{l}\text { Heterogeneity: } \text { Tau }^{2}=0.00 ; \mathrm{Chi}^{2}=0.85, \mathrm{df}=2(P=0.65) ; \mathrm{l}^{2}=0 \% \\
\text { Test for overall effect: } Z=2.88(P=0.004)\end{array}$}} \\
\hline & & & & & & & & & \\
\hline \multicolumn{10}{|c|}{ 2.1.6 Venous thrombosis (Grade $\geqslant 3$ ) } \\
\hline OLIVIA & 3 & 41 & 6 & 39 & $31.1 \%$ & $0.48[0.13,1.77]$ & & & \\
\hline TRIBE & 18 & 252 & 15 & 256 & $68.9 \%$ & $1.22[0.63,2.37]$ & & & \\
\hline Subtotal $(95 \% \mathrm{Cl})$ & & 293 & & 295 & $100.0 \%$ & $0.91[0.39,2.14]$ & & & \\
\hline & 21 & & & & & & & & \\
\hline \multirow{2}{*}{\multicolumn{10}{|c|}{$\begin{array}{l}\text { Heterogeneity: } \text { Tau }^{2}=0.16 ; \mathrm{Ch}^{2}=1.57, \mathrm{df}=1(P=0.21) ; \mathrm{I}^{2}=36 \% \\
\text { Test for overall effect: } Z=0.22(P=0.83)\end{array}$}} \\
\hline & & & & & & & & & \\
\hline & & & & & & & $\begin{array}{ll} & 1 \\
0.1 & 0.2\end{array}$ & 0.51 & $\begin{array}{lll}1 & 5 & 10\end{array}$ \\
\hline
\end{tabular}

Fig. 7. Forest plot for adverse events.

makes the application of a more aggressive regimen crucial for patients in conversion therapy [2]. Cytotoxic drug combined with targeted agents is the new and effective choice to improve the rate of conversion.

Findings in this meta-analysis showed that FOLFOXIRI-Bev significantly increased the R0 resection rate of overall metastases and liver metastases (30\% and $128 \%$, respectively) over the doublet chemotherapy plus Bev. A number of studies have shown a great superiority in conversion rate with FOLFOXIRI-Bev. The resection of metastases was the potentially curative therapy of mCRC $[3,4]$. A pooled analysis of 29 published trials indicated that the resection rate of metastases (any site) was $9.3 \%$ and the resection rate of liver metastases was $18 \%$ in FOLFIRI-Bev regimen [31]. Meanwhile, a pooled analysis of patients with liverlimited mCRC, which pooled results of three trials and showed that FOLFOXIRI-Bev had considerable R0 resection rates and survival benefits [32]. Another pooled analysis of 11 studies manifested the R0 resection rate of overall metastases and liver metastases was $28.1 \%$ and $54.7 \%$, respectively, in FOLFOXIRI-Bev regimen [17]. These studies have shown consistently, either directly or indirectly, that FOLFOXIRI had a higher conversion rate. 
In addition, a higher ORR in FOLFOXIRI-Bev regimen implies a higher possibility of metastases resection. Due to the regenerative capacity of the liver, portal vein embolization and two-stage hepatectomy can be used to increase resectability. Preoperative portal vein thrombosis is a technique that occluded the portal system on one side and causes contralateral lobule hypertrophy, thus stimulate liver regeneration before hepatectomy. Two-stage hepatectomy is the resection of one side of liver in first-stage, followed by a second-stage resection of the other side of the liver after liver regeneration, which often used in bilateral multinodular colorectal liver metastases that are considered unresectable in one hepatectomy. During the period of liver regeneration, the use of a regimen with high response rate can further improve the resectability. Over the past decades, the definition of resectable metastases remains unclear and the surgical selection criteria have been expanded, then the liver metastases surgical management have a tendency to smaller resection margins and aggressive surgeries [33]. These emerging surgical techniques and conceptions offer more opportunities to extend the benefits of surgery to those previously considered unresectable. In our study, FOLFOXIRI-Bev prolonged the PFS and OS in patients with MCRC, even in patients who failed conversion. It means that even if the conversion therapy fails, the FOLFOXIRI-Bev would bring clear survival benefits. Although the numerical value of pooled OS did not change significantly from the OS in the TRIBE trial, the reliability of the OS benefit was increased. However, OS as a secondary endpoint, differences in subsequent therapies may affect the OS benefit, thus the OS benefit needs further study.

Subgroup analyses based on gene mutations were performed in this study, and the differences in survival benefits for left-side and right-side colon cancers was reported in TRIBE and CHARTA trials. The results of the subgroup analysis showed that the benefits of the FOLFOXIRI plus Bev regimen were not related to the RAS mutation status. However, the RAS wild-type cohort probably included the BRAF-mutant cases. And the TRIBE trial also reported no significant differences in the therapeutic effects of the RAS and BRAF molecular subgroups. Unfortunately, there was no data of R0 resection rates, hence the difference of conversion between two regimens in molecular subgroup could not be evaluated accurately. In colorectal cancer, European Society of Medical Oncology (ESMO) has recommended FOLFOXIRI plus Bev regimen for patients with RAS wild-type right-sided tumors for the purpose of cytoreduction. In the CHARTA trial, PFS for left-sided tumors was 12 months and 10.4 months (3-drugs + Bev and 2-drugs + Bev, respectively, HR=0.73, 95\% CI 0.53-1.00), and PFS for right-sided tumors was 10.7 months and 8.2 months (3-drugs + Bev and 2-drugs + Bev, respectively, HR=0.81, 95\% CI 0.47-1.38). In the TRIBE trial, FOLFOXIRI-Bev prolonged OS in the right-sided tumors (HR=0.68, 95\% CI 0.47-0.99) compared with the 2-drugs plus $\mathrm{Bev}$, and OS was not significantly different in the left-sided tumors (HR $=0.88,95 \%$ CI 0.68 1.14). However, these non-statistically significant results of these subgroup analyses need to be interpreted carefully, because it does not take into account mutations in RAS and other genes as well as the principle of randomization were not ensured.

Adverse events could be the most important reason for restricting the choice of the FOLFOXIRI-Bev. The pooled RR of OLIVIA and STEAM trial demonstrated that the incidence of any Grade $\geq 3$ adverse events was similar in two regimens. Moreover, the TRIBE trial demonstrated that FOLFOXIRI-Bev did not increase treatment-related serious adverse events over FOLFIRI-Bev (20.4\% versus 19.7\%) [24]. In the result of OLIVIA, STEAM and TRIBE trials, there was no difference in the incidence of fatal adverse events between two groups. Additionally, the bevacizumab-related adverse events did not differ for different chemotherapy regimens. The high incidence of neutropenia and diarrhea is a noteworthy issue, and a meta-analysis showed that patient's withdrawal due to adverse events was more in the FOLFOXIRI \pm Bev group than that in FOLFOX \pm Bev /FOLFIRI \pm Bev group [34]. Based on intent-to-treat analysis, the STEAM trial reported TEAE leading to withdrawal with $41 \%$ and $38 \%$ for the 3-drug plus Bev and 2-drug plus Bev, respectively. However, several trials and reviews, including the RCTs included in this meta-analysis, suggested that the toxicity from FOLFOXIRI-Bev is tolerable and manageable $[15,35,36]$. And the management 


\section{Cellular Physiology Cell Physiol Biochem 2018;48:1870-1881

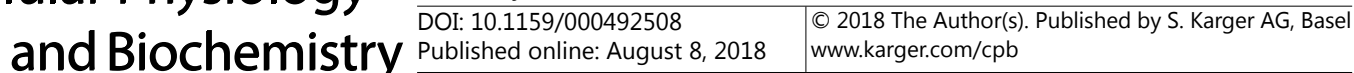

Shui et al.: FOLFOXIRI plus Bevacizumab in mCRC Conversation Therapy

of adverse events of FOLFOXIRI-Bev was summarized in a review [37]. For diarrhea, loperamide, probiotics, octreotide or tincture of opium may be effective prevention agents. For neutropenia, the prevention using granulocyte colony-stimulating factor (G-CSF) can be a choice in patients who previously experienced febrile neutropenia. In short, adverse events should be closely monitored and managed to reduce treatment-related discontinuation.

Assessing the feasibility of FOLFOXIRI-Bev regimen in conversion therapy and choosing the appropriate patients have become a matter of great concern in recent years. An abstract of the METHEP-2 randomized trial reported that the first-line FOLFOXIRI plus targeted agents (Bev or cetuximab depends on RAS status) showed a higher R0/R1 resection rate than the doublet regimen (FOLFIRI or FOLFOX) plus targeted agents in mCRC patients, with statistically significant OS benefit [38]. To some extent, this trial implied the superiority of FOLFOXIRI-Bev in conversion therapy. However, it needs to be further reported the detailed data of R0 resection rate as well as the direct comparison data of FOLFOXIRI plus Bev and doublet regimen plus Bev. The ongoing CAIR05 study, a multicenter, phase 3 RCT, was designed to select the optimal conversion therapy regimen, comparing the efficacy between doublet regimen plus Bev and triplet regimen plus Bev, in mCRC patients with RAS mutation [39]. A meta-analysis showed that first-line cetuximab/panitumumab plus chemotherapy increased ORR and OS compared with Bev plus chemotherapy in mCRC patients with RAS wild-type. However, there was no difference in resection rate and PFS between the two regimens [40]. Given that epidermal growth factor receptor (EGFR) inhibitors are less effective in mCRC patients with RAS or BRAF mutations [41-43], FOLFOXIRI-Bev could be a viable option in conversion therapy for mCRC patients with RAS or BRAF mutations [37, 44].

It is noteworthy that alternative chemotherapy using three drugs may not bring clinical benefits as intensive triplet chemotherapy. The STEAM trial designed a sequential sFOLFOXIRI-Bev arm, which was not included in this meta-analysis, and the arm used alternating doublet chemotherapy (alternating FOLFOX and FOLFIRI every 4 weeks) plus Bev. It showed that there was no difference in PFS (HR 0.7, 95\% CI 0.47-1.05), OS (HR 1.00, 95\% CI 0.65-1.53) and R0 resection rate (RR 1.38, 95\% CI 0.50-3.81) between alternating doublet chemotherapy plus Bev and doublet chemotherapy plus Bev [26, 29].

To our knowledge, this is the first meta-analysis to directly compare which of the two regimens is more effective and tolerable in conversion therapy. Several studies that not focused on the conversion therapy have been published: two pooled analyzes that included many single-arm trials or cohort studies evaluated the efficacy of FOLFOXIRI-Bev or doublet chemotherapy plus Bev independently, without direct comparison data of others regimens $[16,25]$. And three systematic reviews [27, 38, [45]] showed the superiority of FOLFOXIRI plus targeted agents, included Bev, Cetuximab and Panitumumab, which had no head-tohead comparison or had no pooled data of $\mathrm{R} 0$ resection rate.

Limitation of this meta-analysis should be pointed out. Firstly, the small sample size, only four RCTs were included, and that was insufficient to do sensitivity analysis and Begg tests. Secondly, the primary endpoint of the trial and the reported results, only the OLIVIA trial was designed with R0 resection as the primary endpoint. And the incidence of specific adverse events was not reported in the STEAM and CHARTA trials. Thirdly, the differences in patient characteristics. For example, OLIVIA enrolled patients with only liver metastases, whereas other trials enrolled patients without this limitation. This may also be the reason that the R0 resection rate as high as 54\% in OLIVIA trail and other trials only $15 \%-20 \%$. Unfortunately, we failed to retrieve other clinical trials that directly compared triplet chemotherapy plus Bev with doublet chemotherapy plus Bev in liver-limited metastatic colorectal cancer patients, including retrospective studies. Finally, we only included the present published trial data, without the analysis of individual patients data. However, this meta-analysis directly and systematically compared the triplet regimen plus Bev with doublet regimen plus Bev, providing a high level of evidence for the feasibility and superiority of the FOLFOXIRI plus Bev in conversion therapy. 


\section{Cellular Physiology Cell Physiol Biochem 2018;48:1870-1881 \begin{tabular}{cl|l} 
and BiOChemistry & $\begin{array}{l}\text { DOI: 10.1159/000492508 } \\
\text { Published online: August 8, } 2018\end{array}$ & $\begin{array}{l}\text { (c) } 2018 \text { The Author(s). Published by S. Karger AG, Basel } \\
\text { www.karger.com/cpb }\end{array}$
\end{tabular}}

\section{Conclusion}

Triplet chemotherapy plus Bev significantly improved the R0 resection rates, ORR, PFS and OS in comparison with doublet chemotherapy plus Bev in conversion therapy for mCRC patients, with a higher risk of neutropenia and diarrhea.

\section{Disclosure Statement}

No conflicts of interest were declared.

\section{References}

1 Siegel RL, Miller KD, Jemal A: Cancer Statistics, 2017. CA Cancer J Clin 2017;67:7-30.

$\checkmark 2$ Van Cutsem E, Cervantes A, Adam R, Sobrero A, Van Krieken JH, Aderka D, Aranda Aguilar E, Bardelli A, Benson A, Bodoky G, Ciardiello F, D’Hoore A, Diaz-Rubio E, Douillard JY, Ducreux M, Falcone A, Grothey A, Gruenberger T, Haustermans K et al.: ESMO consensus guidelines for the management of patients with metastatic colorectal cancer. Ann Oncol 2016;27:1386-1422.

-3 Abdalla EK, Bauer TW, Chun YS, D’Angelica M, Kooby DA, Jarnagin WR: Locoregional surgical and interventional therapies for advanced colorectal cancer liver metastases: expert consensus statements. HPB (Oxford) 2013;15:119-130.

4 Patel D, Townsend AR, Karapetis C, Beeke C, Padbury R, Roy A, Maddern G, Roder D, Price TJ: Is Survival for Patients with Resectable Lung Metastatic Colorectal Cancer Comparable to Those with Resectable Liver Disease? Results from the South Australian Metastatic Colorectal Registry. Ann Surg Oncol 2016;23:36163622.

5 Sharma S, Camci C, Jabbour N: Management of hepatic metastasis from colorectal cancers: an update. J Hepatobiliary Pancreat Surg 2008;15:570-580.

-6 Choti MA, Sitzmann JV, Tiburi MF, Sumetchotimetha W, Rangsin R, Schulick RD, Lillemoe KD, Yeo CJ, Cameron JL: Trends in Long-Term Survival Following Liver Resection for Hepatic Colorectal Metastases. Annals of Surgery 2002;235:759-766.

7 Shah SA, Bromberg R, Coates A, Rempel E, Simunovic M, Gallinger S: Survival after liver resection for metastatic colorectal carcinoma in a large population. J Am Coll Surg 2007;205:676-683.

-8 Van Cutsem E, Cervantes A, Nordlinger B, Arnold D: Metastatic colorectal cancer: ESMO Clinical Practice Guidelines for diagnosis, treatment and follow-up. Ann Oncol 2014;25 Suppl 3:iii1-9.

-9 Adam R, Delvart V, Pascal G, Valeanu A, Castaing D, Azoulay D, Giacchetti S, Paule B, Kunstlinger F, Ghemard O, Levi F, Bismuth H: Rescue surgery for unresectable colorectal liver metastases downstaged by chemotherapy: a model to predict long-term survival. Ann Surg 2004;240:644-657; discussion 657-648.

$>10$ Morris EJ, Forman D, Thomas JD, Quirke P, Taylor EF, Fairley L, Cottier B, Poston G: Surgical management and outcomes of colorectal cancer liver metastases. Br J Surg 2010;97:1110-1118.

11 Maeda Y, Shinohara T, Nagatsu A, Futakawa N, Hamada T: Long-Term Outcomes of Conversion Hepatectomy for Initially Unresectable Colorectal Liver Metastases. Ann Surg Oncol 2016;23 Suppl 2:S242-248.

12 Benson AB, 3rd, Venook AP, Cederquist L, Chan E, Chen YJ, Cooper HS, Deming D, Engstrom PF, Enzinger PC, Fichera A, Grem JL, Grothey A, Hochster HS, Hoffe S, Hunt S, Kamel A, Kirilcuk N, Krishnamurthi S, Messersmith WA, Mulcahy MF et al.: Colon Cancer, Version 1.2017, NCCN Clinical Practice Guidelines in Oncology. J Natl Compr Canc Netw 2017;15:370-398.

13 Masi G, Vasile E, Loupakis F, Cupini S, Fornaro L, Baldi G, Salvatore L, Cremolini C, Stasi I, Brunetti I, Fabbri MA, Puglisi M, Trenta P, Granetto C, Chiara S, Fioretto L, Allegrini G, Crino L, Andreuccetti M, Falcone A: Randomized trial of two induction chemotherapy regimens in metastatic colorectal cancer: an updated analysis. J Natl Cancer Inst 2011;103:21-30.

14 Falcone A, Ricci S, Brunetti I, Pfanner E, Allegrini G, Barbara C, Crino L, Benedetti G, Evangelista W, Fanchini L, Cortesi E, Picone V, Vitello S, Chiara S, Granetto C, Porcile G, Fioretto L, Orlandini C, Andreuccetti M, Masi G: Phase III trial of infusional fluorouracil, leucovorin, oxaliplatin, and irinotecan (FOLFOXIRI) compared with infusional fluorouracil, leucovorin, and irinotecan (FOLFIRI) as first-line treatment for metastatic colorectal cancer: the Gruppo Oncologico Nord Ovest. J Clin Oncol 2007;25:1670-1676. 


\section{Cellular Physiology Cell Physiol Biochem 2018;48:1870-1881 \begin{tabular}{l|l} 
and Biochemistry & DOI: 10.1159/000492508 \\
Published 2018 The Author(s). Published by S. Karger AG, Basel \\
www.karger.com/cpb
\end{tabular}

15 Xu W, Kuang M, Gong Y, Cao C, Chen J, Tang C: Survival benefit and safety of the combinations of FOLFOXIRI +/- bevacizumab versus the combinations of FOLFIRI +/- bevacizumab as first-line treatment for unresectable metastatic colorectal cancer: a meta-analysis. Onco Targets Ther 2016;9:4833-4842.

-16 Yamazaki K, Nagase M, Tamagawa H, Ueda S, Tamura T, Murata K, Eguchi Nakajima T, Baba E, Tsuda M, Moriwaki T, Esaki T, Tsuji Y, Muro K, Taira K, Denda T, Funai S, Shinozaki K, Yamashita H, Sugimoto N, Okuno T et al.: Randomized phase III study of bevacizumab plus FOLFIRI and bevacizumab plus mFOLFOX6 as first-line treatment for patients with metastatic colorectal cancer (WJOG4407G). Ann Oncol 2016;27:15391546.

17 Tomasello G, Petrelli F, Ghidini M, Russo A, Passalacqua R, Barni S: FOLFOXIRI Plus Bevacizumab as Conversion Therapy for Patients With Initially Unresectable Metastatic Colorectal Cancer: A Systematic Review and Pooled Analysis. JAMA Oncol 2017;3:e170278.

18 Higgins JPT GS: Cochrane Handbook for Systematic Reviews of Interventions Version 5.1.0 [updated March 2011]. The Cochrane Collaboration, 2011

19 Arbyn M, Redman CWE, Verdoodt F, Kyrgiou M, Tzafetas M, Ghaem-Maghami S, Petry K-U, Leeson S, Bergeron C, Nieminen P, Gondry J, Reich O, Moss EL: Incomplete excision of cervical precancer as a predictor of treatment failure: a systematic review and meta-analysis. The Lancet Oncology 2017;10.1016/ s1470-2045(17)30700-3.

20 Higgins JP, Thompson SG, Deeks JJ, Altman DG: Measuring inconsistency in meta-analyses. Bmj 2003;327:557-560.

21 DerSimonian R, Laird N: Meta-analysis in clinical trials revisited. Contemp Clin Trials 2015;45:139-145.

22 Begg CB, Mazumdar M: Operating characteristics of a rank correlation test for publication bias. Biometrics 1994;50:1088-1101.

23 Egger M, Davey Smith G, Schneider M, Minder C: Bias in meta-analysis detected by a simple, graphical test. Bmj 1997;315:629-634.

24 Loupakis F, Cremolini C, Masi G, Lonardi S, Zagonel V, Salvatore L, Cortesi E, Tomasello G, Ronzoni M, Spadi R, Zaniboni A, Tonini G, Buonadonna A, Amoroso D, Chiara S, Carlomagno C, Boni C, Allegrini G, Boni L, Falcone A: Initial therapy with FOLFOXIRI and bevacizumab for metastatic colorectal cancer. N Engl J Med 2014;371:1609-1618.

25 Gruenberger T, Bridgewater J, Chau I, Garcia Alfonso P, Rivoire M, Mudan S, Lasserre S, Hermann F, Waterkamp D, Adam R: Bevacizumab plus mFOLFOX-6 or FOLFOXIRI in patients with initially unresectable liver metastases from colorectal cancer: the OLIVIA multinational randomised phase II trial. Ann Oncol 2015;26:702-708.

26 Bendell JC, Tan BR, Reeves JA, Xiong H, Somer BG, Lenz H-J, Hochster HS, Scappaticci F, Sommer N, Day B-m, Hurwitz H: Overall response rate (ORR) in STEAM, a randomized, open-label, phase 2 trial of sequential and concurrent FOLFOXIRI-bevacizumab (BEV) vs FOLFOX-BEV for the first-line (1L) treatment (tx) of patients (pts) with metastatic colorectal cancer (mCRC). Journal of Clinical Oncology 2016;34:492-492.

-27 Schmoll H-J, Meinert FM, Cygon F, Garlipp B, Junghanss C, Leithäuser M, Vogel A, Schaefers M, Kaiser U, Hoeffkes H-G, Florschütz A, Rüssel J, Kanzler S, Edelmann T, Forstbauer H, Goehler T, Hannig C, Hildebrandt B, Steighardt J, Stein A: “CHARTA”: FOLFOX/Bevacizumab vs. FOLFOXIRI/Bevacizumab in advanced colorectal cancer-Final results, prognostic and potentially predictive factors from the randomized Phase II trial of the AIO. Journal of Clinical Oncology 2017;35:3533-3533.

28 Cremolini C, Loupakis F, Antoniotti C, Lonardi S, Masi G, Salvatore L, Cortesi E, Tomasello G, Spadi R, Zaniboni A, Tonini G, Barone C, Vitello S, Longarini R, Bonetti A, D’Amico M, Di Donato S, Granetto C, Boni L, Falcone A: Early tumor shrinkage and depth of response predict long-term outcome in metastatic colorectal cancer patients treated with first-line chemotherapy plus bevacizumab: results from phase III TRIBE trial by the Gruppo Oncologico del Nord Ovest. Ann Oncol 2015;26:1188-1194.

$\checkmark 29$ Hurwitz H, Tan BR, Reeves JA, Xiong HQ, Somer BG, Lenz H-J, Hochster HS, Scappaticci F, Palma JF, Mancao C, Lee JJ, Nicholas A, Sommer N, Bendell JC: Updated efficacy, safety, and biomarker analyses of STEAM, a randomized, open-label, phase II trial of sequential (s) and concurrent (c) FOLFOXIRI-bevacizumab (BV) vs FOLFOX-BV for first-line (1L) treatment ( $\mathrm{tx}$ ) of patients with metastatic colorectal cancer (mCRC). J Clin Oncol 2017;35:657-657.

-30 Cremolini C, Loupakis F, Antoniotti C, Lupi C, Sensi E, Lonardi S, Mezi S, Tomasello G, Ronzoni M, Zaniboni A, Tonini G, Carlomagno C, Allegrini G, Chiara S, D’Amico M, Granetto C, Cazzaniga M, Boni L, Fontanini G, Falcone A: FOLFOXIRI plus bevacizumab versus FOLFIRI plus bevacizumab as first-line treatment of 


\section{Cellular Physiology Cell Physiol Biochem 2018;48:1870-1881 \begin{tabular}{l|l} 
and Biochemistry & DOI: 10.1159/000492508 \\
Published 2018 The Author(s). Published by S. Karger AG, Basel \\
www.karger.com/cpb
\end{tabular}

patients with metastatic colorectal cancer: updated overall survival and molecular subgroup analyses of the open-label, phase 3 TRIBE study. Lancet Oncol2015;16:1306-1315.

-31 Petrelli F, Borgonovo K, Cabiddu M, Ghilardi M, Lonati V, Maspero F, Sauta MG, Beretta GD, Barni S: FOLFIRIbevacizumab as first-line chemotherapy in 3500 patients with advanced colorectal cancer: a pooled analysis of 29 published trials. Clin Colorectal Cancer 2013;12:145-151.

-32 Cremolini C, Casagrande M, Loupakis F, Aprile G, Bergamo F, Masi G, Moretto RR, Pietrantonio F, Marmorino F, Zucchelli G, Tomasello G, Tonini G, Allegrini G, Granetto C, Ferrari L, Urbani L, Cillo U, Pilati P, Sensi E, Pellegrinelli A et al.: Efficacy of FOLFOXIRI plus bevacizumab in liver-limited metastatic colorectal cancer: A pooled analysis of clinical studies by Gruppo Oncologico del Nord Ovest. Eur J Cancer 2017;73:74-84.

-33 Cloyd JM, Aloia TA: Hammer versus Swiss Army knife: Developing a strategy for the management of bilobar colorectal liver metastases. Surgery 2017;162:12-17.

-34 Marques RP, Duarte GS, Sterrantino C, Pais HL, Quintela A, Martins AP, Costa J: Triplet (FOLFOXIRI) versus doublet (FOLFOX or FOLFIRI) backbone chemotherapy as first-line treatment of metastatic colorectal cancer: A systematic review and meta-analysis. Crit Rev Oncol Hematol 2017;118:54-62.

-35 Stein A, Atanackovic D, Hildebrandt B, Stubs P, Brugger W, Hapke G, Steffens CC, Illerhaus G, Bluemner E, Stohlmacher J, Bokemeyer C: Upfront FOLFOXIRI+bevacizumab followed by fluoropyrimidin and bevacizumab maintenance in patients with molecularly unselected metastatic colorectal cancer. Br J Cancer 2015;113:872-877.

-36 Fernandes GDS, Braghiroli MI, Artioli M, Paterlini A, Teixeira MC, Gumz BP, Girardi DDM, Braghiroli OFM, Costa FP, Hoff PM: Combination of Irinotecan, Oxaliplatin and 5-Fluorouracil as a Rechallenge Regimen for Heavily Pretreated Metastatic Colorectal Cancer Patients. J Gastrointest Cancer 2017;10.1007/s12029017-0001-3. DOI:10.1007/s12029-017-0001-3

-37 Loupakis F, Stein A, Ychou M, Hermann F, Salud A, Österlund P: A Review of Clinical Studies and Practical Guide for the Administration of Triplet Chemotherapy Regimens with Bevacizumab in First-line Metastatic Colorectal Cancer. Targeted Oncology 2016;11:293-308.

-38 Ychou M, Rivoire M, Thezenas S, Guimbaud R, Ghiringhelli F, Mercier-Blas A, Mineur L, Francois E, Khemissa F, Moussata D, Becouarn Y, Houyau P, Aparicio T, Adam R, Galais M-P, Audemar F, Assenat E, Stanbury T, Bouche O: FOLFIRINOX combined to targeted therapy according RAS status for colorectal cancer patients with liver metastases initially non-resectable: A phase II randomized Study-Prodige 14 - ACCORD 21 (METHEP-2), a unicancer GI trial. Journal of Clinical Oncology 2016;34:3512-3512.

-39 Huiskens J, van Gulik TM, van Lienden KP, Engelbrecht MR, Meijer GA, van Grieken NC, Schriek J, Keijser A, Mol L, Molenaar IQ Verhoef C, de Jong KP, Dejong KH, Kazemier G, Ruers TM, de Wilt JH, van Tinteren H, Punt CJ: Treatment strategies in colorectal cancer patients with initially unresectable liver-only metastases, a study protocol of the randomised phase 3 CAIR05 study of the Dutch Colorectal Cancer Group (DCCG). BMC Cancer 2015;15:365.

40 Heinemann V, Rivera F, O’Neil BH, Stintzing S, Koukakis R, Terwey J-H, Douillard J-Y: A study-level metaanalysis of efficacy data from head-to-head first-line trials of epidermal growth factor receptor inhibitors versus bevacizumab in patients with RAS wild-type metastatic colorectal cancer. Eu J Cancer 2016;67:1120.

-41 Dahabreh IJ, Terasawa T, Castaldi PJ, Trikalinos TA: Systematic review: Anti-epidermal growth factor receptor treatment effect modification by KRAS mutations in advanced colorectal cancer. Ann Intern Med 2011;154:37-49.

42 Rowland A, Dias MM, Wiese MD, Kichenadasse G, McKinnon RA, Karapetis CS, Sorich MJ: Meta-analysis of BRAF mutation as a predictive biomarker of benefit from anti-EGFR monoclonal antibody therapy for RAS wild-type metastatic colorectal cancer. Br J Cancer 2015;112:1888-1894.

43 Pietrantonio F, Petrelli F, Coinu A, Di Bartolomeo M, Borgonovo K, Maggi C, Cabiddu M, Iacovelli R, Bossi I, Lonati V, Ghilardi M, de Braud F, Barni S: Predictive role of BRAF mutations in patients with advanced colorectal cancer receiving cetuximab and panitumumab: a meta-analysis. Eur J Cancer 2015;51:587-594.

44 Zhou M, Yu P, Hernick Davin DB, Li Y, Wang Y, Fu L, Zhang J: Is FOLFOXIRI alone or combined with targeted therapy administered as first-line treatment a reasonable choice for most patients with mCRC? Systematic review and network meta-analysis. Oncotarget 2017;8:62339-62348.

45 Zhou M, Yu P, Qu J, Chen Y, Zhou Y, Fu L, Zhang J: Efficacy of Bevacizumab in the First-Line Treatment of Patients with RAS Mutations Metastatic Colorectal Cancer: a Systematic Review and Network MetaAnalysis. Cell Physiol Biochem 2016;40:361-369. 